a. Servicio de Crecimiento y Desarrollo.

b. Servicio de Ortopedia y Traumatología.

c. Servicio de Diagnóstico por Imágenes.

Hospital "Prof. Dr.

Juan P. Garrahan",

Buenos Aires, Argentina.

d. Servicio de Ortopedia

y Traumatología, Sanatorio Allende, Córdoba, Argentina.

e. Servicio de Diagnóstico por Imágenes, Hospital Provincial M. y L. de la Vega, Moreno, Buenos Aires, Argentina.

f. Servicio de Diagnóstico por Imágenes, Asociación Española, Comodoro Rivadavia, Chubut, Argentina.

g. Hospital de Niños

Víctor J. Vilela, Rosario, Argentina.

h. Servicio de Diagnóstico por Imágenes, Hospital de Niños Dr. Orlando Alassia, Santa Fe, Argentina.

i. Servicio de Ortopedia y Traumatología, Hospital de Niños Roberto del Río, Santiago, Chile.

j. División Radiodiagnóstico, Hospital General de Niños Pedro de Elizalde, Buenos Aires, Argentina.

k. Servicio de Ortopedia y Traumatología, Hospital del Trauma, Paraguay.

1. Servicio de Ortopedia y Traumatología, Capacitaciones en Ortopedia y Traumatología Infantil, Santiago, Chile.

m. Servicio de Ortopedia y Traumatología, Hospital de Niños Dr. Ricardo Gutiérrez Buenos Aires, Argentina.

n. Facultad de Ciencias Sociales, Carrera de Sociología, Cátedra de Metodología y Técnicas de Investigación I, II y III, Universidad de Buenos Aires, Buenos Aires, Argentina.

Correspondencia:

Dra. Silvia Caino,

scaino@garrahan.gov.ar

Financiamiento:

Ninguno.

Conflicto de intereses:

Ninguno que declarar.

Recibido: 30-5-2018

Aceptado: 17-9-2018

\title{
Recomendaciones para el seguimiento de niños con asimetría en la longitud de los miembros inferiores: consenso de expertos
} Recommendations for the follow-up of children with leg length discrepancy: expert consensus

\author{
Dra. Silvia Caino ${ }^{a}$ Dra. Rosario Ramos Mejía ${ }^{a}$, Dr. Rodolfo Goyeneche ${ }^{b}$,

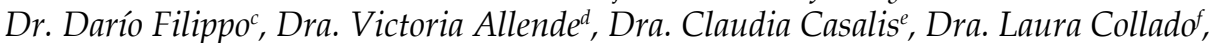 \\ Dr. Martín D'Elíag, Dr. Guillermo Fernández ${ }^{h}$, Dra. Mónica Galeanoc, \\ Dr. Juan C. Hernándezi, Dr. Leopoldo Lonegro ${ }^{j}$, Dra. Juliana Lostrac, \\ Dr. Javier Masquijo ${ }^{d}$ Dr. Horacio Miscione ${ }^{b}$, Dr. Alberto Navarro Fretes ${ }^{k}$, \\ Dra. Dalia Sepúlveda Arriagadal, Dr. Eduardo Stéfano ${ }^{m}$, Lic. Graciela Infesta ${ }^{n}$ y \\ Dra. Virginia Fano ${ }^{a}$
}

\section{RESUMEN}

La asimetría de la longitud de los miembros inferiores es una afección en la cual la longitud de una pierna difiere de la contralateral, motivo de consulta frecuente en el consultorio del pediatra y del ortopedista infantil. Elobjetivo de nuestro trabajo fue desarrollar recomendaciones de seguimiento, planificación prequirúrgica y tratamiento de niños con asimetría de la longitud de los miembros inferiores mediante el consenso de expertos.

Material y métodos. Se utilizó el método Delphi. Un grupo coordinador seleccionó el panel de expertos, diseñó y analizó cada una de las rondas de consulta. Los cuestionarios semiestructurados fueron enviados por correo electrónico en forma personalizada. Se estableció como criterio de consenso un acuerdo entre los expertos $\geq 80 \%$. En cada una de las rondas, se reformularon los aspectos no consensuados y se agregaron nuevos sugeridos en la ronda anterior. Se consideró como medida de estabilidad para concluir la consulta cuando más del $70 \%$ de los expertos no modificó su opinión en rondas sucesivas.

Resultados. Participaron del consenso 8 expertos en ortopedia y 6 en diagnóstico por imágenes. Luegode3rondas deconsulta, selogróelconsenso en 39 recomendaciones referentes a seguimiento, planificación prequirúrgica y tratamiento. Fueron reagrupadas en 32 recomendaciones finales.

Conclusiones. Estas son las primeras recomendaciones para el seguimiento de niños con asimetría de la longitud de los miembros inferiores mediante el consenso de expertos.

Palabras clave: asimetría, miembros inferiores, consenso, guía de práctica clínica.

http:/ / dx.doi.org/10.5546/ aap.2019.94 Texto completo en inglés:

http:/ / dx.doi.org/10.5546/ aap.2019.eng.94

Cómo citar: Caino S, Ramos Mejía R, Goyeneche R, Filippo D, et al. Recomendaciones para el seguimiento de niños con asimetría en la longitud de los miembros inferiores: consenso de expertos. Arch Argent Pediatr 2019;117(2):94-104.

\section{INTRODUCCIÓN}

La asimetría o discrepancia de los miembros inferiores, afección en la cual la longitud y/o el perímetro de una pierna es diferente a la contralateral, es motivo de consulta frecuente en el consultorio del pediatra y/o del ortopedista infantil. Si bien la prevalencia se desconoce $y$, a la fecha, no se ha encontrado un valor límite a partir del cual la asimetría sea considerada patológica, estudios de prevalencias en diferentes poblaciones muestran diferencias de hasta $1,5 \mathrm{~cm}$ en el $30 \%$ de los varones durante el entrenamiento militar sin significación

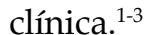

Las asimetrías se clasifican del siguiente modo: a) funcionales, debidas a contracturas articulares, musculares o desejes de los miembros y b) estructurales, por alteración en la longitud ósea. Estas últimas pueden ser congénitas (hipertrofia lateralizada aislada, luxación congénita de caderas, hemimelia) o adquiridas (posfracturas, neurológicas, infecciosas, neoplásicas). ${ }^{4,5}$

El objetivo del tratamiento es igualar la longitud de los miembros actual y en la adultez para evitar complicaciones, tales como actitudes compensatorias, dolor lumbar, escoliosis funcional, artrosis de cadera o alteración de la imagen corporal, en especial, durante la adolescencia., ${ }^{4,6} \mathrm{El}$ tratamiento puede ser médico, realce 
en la pierna corta, o quirúrgico, por elongación del miembro corto, acortamiento del largo o combinación de ambos procedimientos. ${ }^{4,-10}$

Para la planificación quirúrgica, se requiere estimar la discrepancia en la adultez y el momento óptimo de la cirugía. Existen diferentes métodos de predicción, tales como el método de Anderson, Moseley, Multiplier. ${ }^{11-13}$

A pesar de la amplia literatura acerca de los métodos de predicción y técnicas quirúrgicas, no se han encontrado recomendaciones de seguimiento de este grupo de pacientes. El seguimiento se realiza, habitualmente, según la experiencia del lugar de trabajo o del ortopedista.

Por eso, el objetivo de nuestro trabajo fue desarrollar recomendaciones de seguimiento, planificación prequirúrgica y tratamiento de niños con asimetría de la longitud de los miembros inferiores por el consenso de expertos utilizando el método Delphi.

\section{MATERIAL Y MÉTODOS}

Para la elaboración de las recomendaciones, se siguió la metodología Delphi, proceso de comunicación grupal que permite a un grupo de individuos, como un todo, tratar un problema complejo. Su objetivo es obtener el acuerdo entre los expertos sobre el problema planteado. ${ }^{14,15}$

Un grupo coordinador (SC, RRM, VF, RG, DF) diseñó la lista de aspectos para consensuar, seleccionó el panel de expertos y analizó cada una de las rondas de consulta.

Los aspectos para consensuar fueron seguimiento (clínico-radiológico), planificación prequirúrgica y tratamiento. Se realizó una revisión sistemática en Pubmed y Lilacs hasta diciembre de 2016, utilizando "asimetría", "discrepancia", "longitud de miembros inferiores" como motores de búsqueda.

Se invitó a participar del estudio a 17 expertos (10 en ortopedia y 7 en diagnóstico por imágenes). Estos últimos solo participaron del consenso acerca de "solicitud y medición radiológica" para la planificación prequirúrgica. El único criterio de selección de los expertos fue el grado de experiencia ( $\geq 10$ años) en el seguimiento de niños con asimetrías. La totalidad de los expertos en diagnóstico por imágenes y siete de los ortopedistas fueron argentinos, dos de Chile y uno de Paraguay. La distribución de los expertos según el lugar de trabajo, público y/o privado, fue equilibrada.

Se estableció como criterio de consenso un acuerdo entre los expertos $\geq 80 \%$. Se incluyó el $24 \%$ de preguntas opuestas para analizar la confiabilidad de las respuestas. Se consideró como medida de estabilidad, para concluir el Delphi, cuando $>70 \%$ de los expertos no modificaron la respuesta respecto a las rondas anteriores.

El Delphi consistió en una serie de rondas de cuestionarios enviados por correo electrónico, en forma personal, entre diciembre de 2016 y noviembre de 2017. La ronda inicial consistió en una serie de 45 afirmaciones, con escala de respuesta Likert de 5 puntos (opciones de "muy en desacuerdo" a "totalmente de acuerdo"), y 8 preguntas abiertas.

Las rondas siguientes consistieron en reformular los aspectos que no habían alcanzado el consenso teniendo en cuenta los argumentos de los expertos, agregar nuevos aspectos para consensuar sugeridos en la ronda anterior y repreguntar a los expertos que no habían estado de acuerdo con las afirmaciones consensuadas solicitando argumentos.

Finalmente, la lista de recomendaciones acordadas fue revisada por cada uno de los expertos, se las reagrupó y se llegó al documento final.

\section{RESULTADOS}

Participaron del consenso 14 expertos, 8 en ortopedia y 6 en diagnóstico por imágenes, con una mediana de años de experiencia de 20 años (r: 11-43). Luego de 3 rondas, concluyó el proceso de consulta esquematizado en la Figura 1.

En la ronda 1, se consensuaron 22 de 45 afirmaciones. Los expertos recomendaron determinar la etiología de las asimetrías y el patrón de evolución, agruparlas en congénitas y adquiridas, solicitar una radiografía inicial independientemente de la edad del niño, predecir, en, al menos, dos oportunidades, la magnitud de la asimetría en la adultez y el momento de la epifisiodesis, evaluar la altura del realce anualmente y cada 6 meses durante la pubertad, considerar la estatura final estimada en la elección del tratamiento quirúrgico. Cinco de 14 afirmaciones compartidas por los dos paneles de expertos alcanzaron el consenso: solicitar la telemetría de los miembros inferiores en lugar del escanograma e indicar, en la solicitud de la radiografía, la magnitud del realce y los reparos anatómicos para medir cada uno de los segmentos del miembro inferior descritos en la Tabla 1.

En la ronda 2, se acordaron 10 de 23 recomendaciones. Cuatro de los expertos que se mostraron indiferentes y 2 de 3 expertos 
FIgUra 1. Consenso de expertos. Esquema del proceso de consulta

\section{Panel de expertos en ortopedia}

\section{Ronda 1}

Panel de expertos

en diagnóstico por

imágenes

45 afirmaciones

(14/45 a ambos paneles)

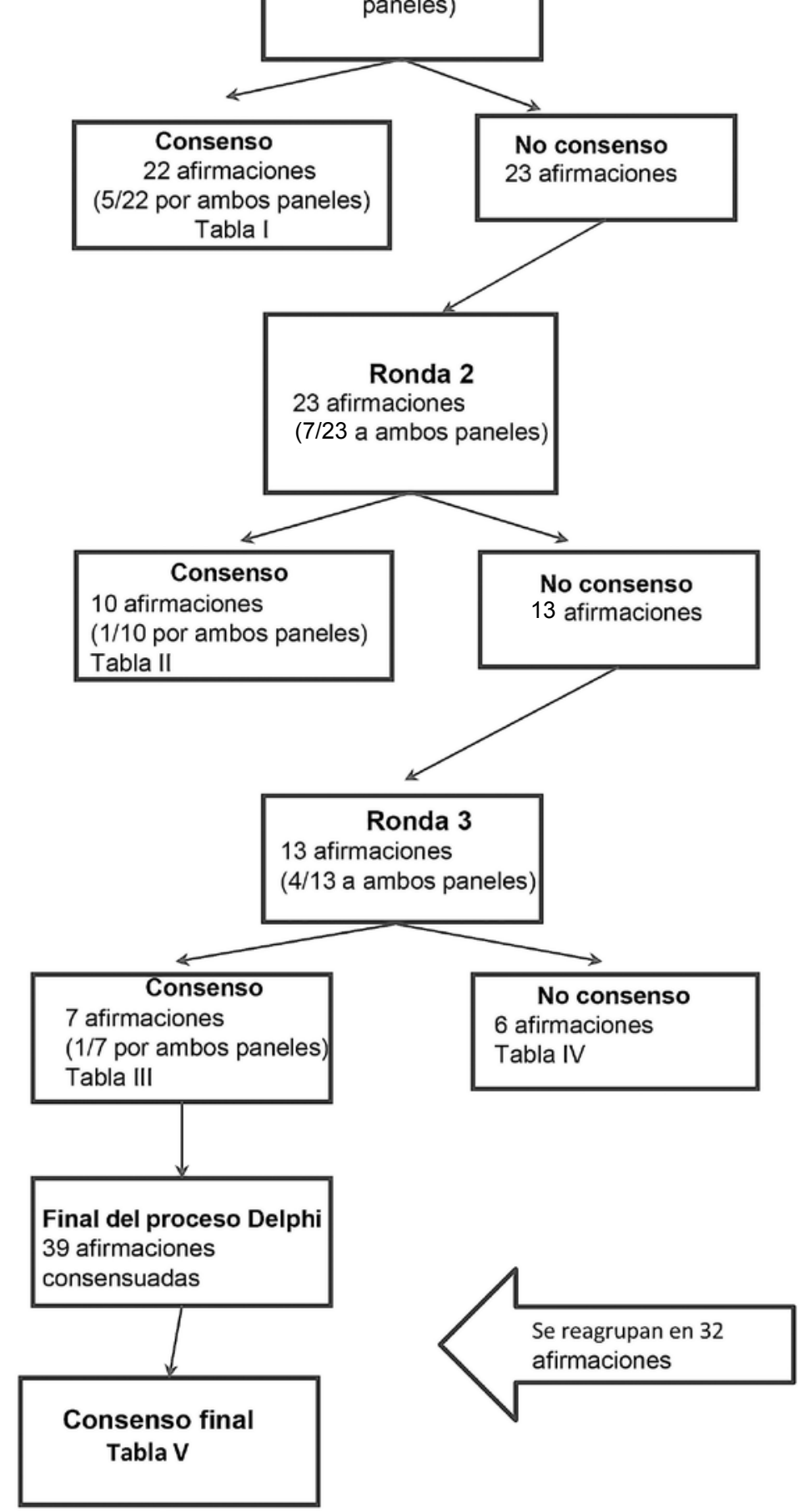


que estuvieron en desacuerdo con afirmaciones consensuadas en la ronda anterior-indicadas con un asterisco $\left(^{*}\right)$ en la Tabla 2 - modificaron su opinión, lo que mejoró el porcentaje de acuerdo. Los nuevos aspectos consensuados fueron la frecuencia de los controles radiológicos, realizar la radiografía en decúbito hasta los 2 o 4 años y luego de pie con realce, indicar la altura del realce por medición clínica y radiológica, realizar la epifisiodesis de la pierna larga en asimetrías predichas en la adultez $>2 \mathrm{~cm}$, incluir al pediatra de cabecera y/o al endocrinólogo infantil en la evaluación del desarrollo puberal.

En la Tabla 3, se resumen las recomendaciones consensuadas en la tercera ronda $(7 / 13)$. Se acordó disminuir la frecuencia de los controles radiológicos en los niños con asimetría actual y predicha en la adultez $<2 \mathrm{~cm}$, predecir el momento de la epifisiodesis, aun si el niño llegaba tarde a la consulta, indicar el realce cuando la pelvis basculaba e incluir a los padres en la decisión del tratamiento quirúrgico. Ambos paneles de expertos acordaron realizar la medición funcional y/o anatómica del miembro inferior dependiendo del compromiso articular y la alteración de ejes.

Los aspectos no consensuados entre los dos paneles de expertos, luego de finalizado el proceso de consulta, fueron los siguientes: 1. Inclusión del pie en la medición radiológica: el $100 \%$ de los expertos en ortopedia recomendaron la inclusión del pie en los niños con afectación de dicho segmento, mientras que el 83,3\% de los expertos en imágenes no la recomendaron. 2. Calibración del sistema de medición radiológica: el $100 \%$ de los expertos en ortopedia recomendaron colocar un reparo a la altura del niño con lo cual calibrar la regla de medición para evitar la distorsión del tamaño de la imagen, que no logró consenso en el panel de expertos en imágenes (el $66,6 \%$ ). En la Tabla 4, se enumeran los aspectos no consensuados y algunos de los argumentos de los expertos.

Las 39 afirmaciones consensuadas fueron reagrupadas en 32 recomendaciones finales, detalladas en la Tabla 5.

\section{DISCUSIÓN}

El Delphi incrementó el consenso incluyendo, excluyendo y modificando recomendaciones en las rondas sucesivas. En aquellos aspectos en los cuales no se logró el acuerdo, este método permitió analizar los argumentos de los expertos.

\section{A) Seguimiento}

Al igual que lo propuesto por Bowen y col., los expertos acordaron que, además de la medición clínica, se solicite una radiografía inicial de los miembros inferiores, independientemente de la edad del niño. ${ }^{9}$ Esto permitiría evaluar la discrepancia ósea actual y, según el método de predicción utilizado, la discrepancia en la adultez.

Respecto al patrón de evolución, Shapiro y col. establecieron cinco. ${ }^{16}$ Los métodos de predicción de discrepancia final y el momento óptimo de la epifisiodesis fueron desarrollados para las asimetrías que seguían un patrón de Shapiro I: patrón lineal ascendente. ${ }^{12,13}$ Sin embargo, los expertos recomendaron, si bien no era lo ideal, utilizar un método de predicción, aunque la asimetría no siguiera la evolución de Shapiro I.

Para la predicción de la asimetría en la adultez y el momento de la epifisiodesis, se describen varios métodos: crecimiento remanente de Menelaus, aritmético de Anderson, de línea recta de Mosley y Multiplier. ${ }^{11-13,18}$ Si bien no hubo acuerdo respecto a la preferencia por algún método, y no se ha encontrado evidencia que demuestre que un método sea más exacto, el $62,5 \%$ de los expertos recomendó utilizar Multiplier. Al igual que lo propuesto por Friend y col., el panel de expertos recomendó realizar la predicción con, al menos, dos métodos diferentes para minimizar el error de estimación. ${ }^{19}$

La predicción del momento de la epifisiodesis puede realizarse con la edad cronológica o con la edad ósea. Es sabido que la edad ósea es mejor indicador del crecimiento remanente teniendo en cuenta la variabilidad individual del inicio puberal. Si bien no se logró un acuerdo en este aspecto, hay autores que recomiendan utilizar la edad ósea especialmente durante el empuje puberal de crecimiento. ${ }^{11,12,20}$ Algunos expertos en ortopedia expresaron la dificultad en la determinación de la edad ósea y recomendaron incluir al pediatra de cabecera y / o al endocrinólogo infantil para evaluar el crecimiento remanente del niño.

Otro aspecto importante para consensuar era la frecuencia del control radiológico y la predicción del momento óptimo de la epifisiodesis. La repetición de las mediciones radiológicas incrementa la precisión de la predicción, pero expone al niño a mayor radiación. Al respecto, el panel de expertos recomendó que la frecuencia del control radiológico dependiera de la etiología, de la magnitud y de la evolución. 
TABLA 1. Aspectos consensuados en la ronda 1

Panel de expertos en ortopedia

Afirmación

Acuerdo (\%) Mediana (rango)

A. Seguimiento y planificación prequirúrgica

Es importante determinar la etiología de la asimetría para definir el seguimiento.

$5(4-5)$

Durante el seguimiento, será importante definir el patrón de evolución (Shapiro) de la asimetría. 87,5

$4,5(3-5)$

Es útil agrupar la etiología de las asimetrías en congénitas y adquiridas.

$5(3-5)$

Además de la evaluación clínica, es obligatorio pedir una radiografía para

la medición inicial (primera consulta), independientemente de la edad del niño.

87,5

$5(4-5)$

Predicción de la discrepancia final

Si bien no es lo ideal, hay que utilizar un método de predicción de discrepancia final, aunque la asimetría no siga el patrón de Shapiro I. ${ }^{16}$

Es necesario utilizar un método de predicción para conocer la discrepancia final al inicio

del seguimiento, independientemente de la edad del niño.

100

Es necesario utilizar un método de predicción para conocer la discrepancia final,

independientemente del tratamiento que se elija.

100

Planificación del momento de la epifisiodesis

Es necesario utilizar un método de predicción para conocer el momento óptimo de la cirugía.

Si bien no es lo ideal, hay que utilizar un método de predicción del momento de la epifisiodesis, aunque la asimetría no siga el patrón de Shapiro I.

Es necesario realizar, al menos, dos predicciones del momento de la epifisiodesis antes

de la cirugía para minimizar el error.

100

100

100

100

\section{B. Tratamiento}

La elección del tratamiento quirúrgico dependerá de la magnitud de la

asimetría actual y predicha en la adultez.

En la elección del tratamiento quirúrgico, se tendrá en cuenta la predicción

de la estatura final del niño.

La altura del realce se evaluará anualmente.

100

$5(4-5)$

100

$5(4-5)$

La altura del realce se evaluará cada 6 meses durante la pubertad.

87,5

$4(3-5)$

\section{Consenso entre ambos paneles de expertos}

Expertos en ortopedia

Expertos en diagnóstico por imágenes

Afirmación

La radiología se considerará adecuada si incluye

las caderas y los tobillos y las rótulas están centradas.

Acuerdo (\%) Mediana (rango) $\quad$ Acuerdo (\%) $\quad$ Mediana (rango)

Se debe solicitar la telemetría de los miembros inferiores

(imagen en una sola radiografía de la totalidad de ambas

extremidades inferiores, desde la pelvis hasta el tobillo)

en lugar del escanograma (tres exposiciones: caderas, rodillas

y tobillos; las tres imágenes quedan impresas en una misma placa).

La medición radiológica del fémur se realiza entre el punto más proximal de la cabeza femoral y el surco intercondíleo.

La medición radiológica de la tibia se realiza entre la eminencia intercondílea y el punto medio de la tibia distal en el tobillo.

$5(1-5)$

100

Se debe indicar en la orden de la radiografía al técnico radiólogo la altura y la localización del realce (pie derecho o izquierdo) de manera de nivelar la pelvis y evitar errores de medición.

La radiología se realizará en decúbito hasta los 2 o 4 años,

según el tamaño del chasis disponible; a partir de entonces, se realizará de pie con realce.

Si existe afectación de los pies, la medición radiológica se realizará desde la cresta ilíaca hasta el piso.

\begin{tabular}{cccc}
100 & $5(4-5)$ & 100 & $5(4-5)$ \\
87,5 & $5(1-5)$ & 83,3 & $5(2-5)$ \\
100 & $5(4-5)$ & 100 & $5(4-5)$ \\
100 & $5(4-5)$ & 83,3 & $4(1-5)$ \\
87,5 & $4,5(2-5)$ & nc & nc \\
100 & $4,5(4-5)$ & nc & nc \\
87,5 & $5(3-5)$ & nc & nc \\
\hline
\end{tabular}

Antes de realizar la medición radiológica de la longitud de los miembros inferiores, es importante calibrar el sistema (en radiografías digitales) utilizando un patrón de referencia.

$\mathrm{nc}=$ no consenso (acuerdo entre los expertos $<80 \%$ ). 
En los niños prepuberales, con asimetría actual y predicha en la adultez $<2 \mathrm{~cm}$, el control radiológico se realizará cada 2 o 3 años evaluando la altura del realce por test de bloques.

\section{B) Opciones terapéuticas}

El objetivo del tratamiento es igualar la longitud de los miembros actual y en la adultez. Algunos autores mencionan cambios biomecánicos compensatorios en las asimetrías de la longitud tan pequeñas como $6 \mathrm{~mm} .{ }^{21,22} \mathrm{Sin}$ embargo, no existe, en la bibliografía, un punto de corte a partir del cual la asimetría es considerada patológica. Desde lo funcional, los expertos consensuaron que la indicación de tratamiento médico (realce en la pierna corta) se recomendaba cuando la pelvis basculaba, independientemente de la magnitud de la asimetría.

Al igual que Gross y Friend, ${ }^{19,23}$ se acordó que la indicación de tratamiento quirúrgico mediante epifisiodesis de la pierna larga (como único tratamiento) se recomendaba en las discrepancias predichas en la adultez $>2 \mathrm{~cm}$. Si bien no se acordó el límite máximo recomendado para

TABla 2. Aspectos consensuados en la ronda 2

Panel de expertos en ortopedia

\section{A. Seguimiento y planificación prequirúrgica}

Durante el seguimiento, será importante definir el patrón de evolución (Shapiro) ${ }^{16}$ de la asimetría. $100^{*}$

Es útil agrupar la etiología de las asimetrías en congénitas y adquiridas.

La frecuencia del control radiológico dependerá de la magnitud y de la evolución de la asimetría.

Durante el seguimiento, es importante evaluar el desarrollo puberal del niño. Se recomienda el

seguimiento junto con el pediatra de cabecera y/o el endocrinólogo infantil.

$100^{*}$
$100^{*}$
87,5

100

$100^{*}$
$100^{*}$
87,5
100

Planificación del momento de la epifisiodesis

Es necesario realizar, al menos, dos predicciones del momento de la epifisiodesis antes de la cirugía

para minimizar el error de predicción.

\section{B. Tratamiento}

La altura del realce se indicará con la medición clínica (test de bloques) y radiológica.

La epifisiodesis se recomienda cuando la asimetría predicha en la adultez es $>2,0 \mathrm{~cm}$.

Para la predicción de la estatura final del niño, se recomienda trabajar en forma conjunta el ortopedista

con el pediatra de cabecera y / o el endocrinólogo infantil.

Para la predicción de la estatura final adulta, se recomienda utilizar el método de Multiplier. ${ }^{13} \mathrm{El}$ 62,5\%

recomienda realizarlo con la edad ósea.

$100^{*}$

87,5

87,5

100

100

Ambos paneles de expertos

Expertos en Expertos en ortopedia diagnóstico por imágenes

Acuerdo $(\%) \quad$ Acuerdo $(\%)$

\section{Afirmación}

Acuerdo (\%)

C. Solicitud y medición radiológica de los miembros inferiores

La radiología se realizará en decúbito hasta los 2 o 4 años (o antes según la colaboración

del niño), de acuerdo con el tamaño del chasis disponible; a partir de entonces,

se realizará de pie (y con realce si está solicitado en la radiografía).**

Se debe indicar en la orden de la radiografía al técnico radiólogo la altura y la

localización del realce (pie derecho o izquierdo) de manera de nivelar la pelvis y

evitar errores de medición.

La radiología se considerará adecuada si incluye las caderas y los tobillos y las rótulas

están centradas.

Se debe agregar en la orden de solicitud de la radiografía que coloquen un patrón de referencia

(regla, cuadrícula, espera radioopaca, etc.) para poder calibrar la regla al realizar la medición.

Antes de realizar la medición radiológica de la longitud de los miembros inferiores,

se debe calibrar el sistema (en radiografías digitales) utilizando un patrón de referencia.

Si existe afectación de los pies, la medición radiológica se realizará desde la cresta ilíaca

hasta el piso.

Para predecir la asimetría en la adultez y el momento óptimo de la epifisiodesis,

se utiliza la longitud funcional.

nc

$100^{*} \mathrm{nc}$

$100 \quad$ nc

* Afirmaciones que fueron revisadas por los expertos y permitieron aumentar el porcentaje de acuerdo.

** Afirmación que fue reformulada según las sugerencias de los panelistas.

nc: no se logró consenso. 
realizar la epifisiodesis, el $75 \%$ de los expertos propuso 5,0 cm como límite superior, luego la elongación de la pierna corta o una combinación de técnicas.

La reducción del crecimiento de la pierna larga, mediante epifisiodesis, puede ser definitiva o transitoria. ${ }^{9,10}$ Existen pocos trabajos que comparan los resultados de ambos métodos a largo plazo. ${ }^{24} \mathrm{Al}$ respecto, los expertos acordaron que la elección de la técnica de epifisiodesis dependiera de la magnitud de la asimetría y el $75 \%$ consideró que, en los niños pequeños con asimetrías importantes, la epifisiodesis transitoria evitaría el uso de realce muy pesado durante los años escolares.

Otro aspecto para tener en cuenta en la elección del método quirúrgico es la predicción de la estatura final. La totalidad de los expertos recomendaron trabajar en conjunto con el pediatra y / o el endocrinólogo infantil en el análisis de la curva del crecimiento. Sin embargo, no se logró establecer el límite inferior de estatura adulta a partir del cual se desestimaría el acortamiento de la pierna larga. Algunos expertos sugirieron el centilo 3, que, para la población argentina, corresponde a $150 \mathrm{~cm}$ y $160 \mathrm{~cm}$ en mujeres y varones, respectivamente. ${ }^{25}$ Otros mencionaron que la estatura final, aunque baja, no sería determinante de la elección del tratamiento quirúrgico, ya que dependería también de la preferencia de los padres y de los adolescentes, analizando en conjunto los riesgos y beneficios de cada procedimiento.

Las complicaciones posepifisiodesis a mediano y largo plazo reportadas son las deformidades angulares secundarias a la epifisiodesis incompleta y la sub- o sobrecorrección. ${ }^{7,26} \mathrm{Al}$ respecto, el $75 \%$ de los expertos recomendó el seguimiento clínico y radiológico cada 4-6 meses hasta que el niño alcance la edad ósea adulta.

\section{C) Solicitud y medición radiológica}

Al igual que Sabharwal y col., se acordó solicitar la telemetría de los miembros inferiores en lugar del escanograma. Si bien las mediciones son comparables, la telemetría permite evaluar

TABla 3. Aspectos consensuados en la ronda 3

Panel de expertos en ortopedia

\begin{tabular}{lc} 
Afirmación & Acuerdo (\%) \\
\hline $\begin{array}{l}\text { A. Seguimiento y planificación prequirúrgica } \\
\text { En los niños con asimetría actual y predicha en la adultez }<2 \mathrm{~cm} \text {, la frecuencia del seguimiento } \\
\text { radiológico puede realizarse cada dos o tres años durante los años prepuberales. }\end{array}$ & 100 \\
Si el niño llega a la consulta ya iniciada la pubertad (consulta tardía), se debe realizar igual, al menos, \\
una predicción del momento de la epifisiodesis.
\end{tabular}

Afirmaciones enviadas a ambos paneles

Expertos en Expertos en ortopedia diagnóstico por imágenes

Afirmación

La medición radiológica del miembro inferior total se realiza entre el punto más proximal de la cabeza femoral y el punto medio distal de la tibia " $\mathrm{y} / \mathrm{o}$ " realizando la sumatoria de los segmentos (tibia + fémur). Esto dependerá de si el niño presenta compromiso articular, alteración de ejes y/o del número de segmentos afectados. ** 
TABla 4. Aspectos no consensuados

\begin{tabular}{llc}
\hline $\begin{array}{c}\text { Expertos en } \\
\text { ortopedia }\end{array}$ & $\begin{array}{c}\text { Expertos en } \\
\text { diagnóstico } \\
\text { por imágenes }\end{array}$ & Comentarios \\
\hline
\end{tabular}

Afirmación
Si existe afectación de los pies,
la medición radiológica se realizará
desde la cresta ilíaca hasta el piso

Se debe colocar un patrón de referencia a la altura del paciente (regla, cuadrícula, esfera radioopaca, etc.) durante la obtención de la radiografía.

Acuerdo (\%) Acuerdo (\%)

100

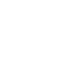

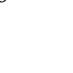


en la misma imagen deformidades angulares, lo que reduce la exposición a la radiación..$^{27} \mathrm{Se}$ recomienda realizar la telemetría con el niño en decúbito hasta los 2 años de edad y luego de pie con realce. El objetivo del uso de realce en la pierna corta es nivelar la pelvis para minimizar el error de medición. Es importante destacar que el médico pediatra u ortopedista será quien indique en la orden al técnico radiólogo la magnitud y localización del realce.

Al momento de realizar la medición radiológica, la distancia del tubo al paciente

TABLA 5. Consenso final

\section{Afirmación}

A. Seguimiento y planificación prequirúrgica

Es importante determinar la etiología de la asimetría para definir el seguimiento.

Es útil agrupar la etiología de las asimetrías en congénitas y adquiridas.

Durante el seguimiento, será importante definir el patrón de evolución (Shapiro) de la asimetría.

Además de la evaluación clínica, es obligatorio solicitar la radiografía de los miembros inferiores para la medición inicial (primera consulta), independientemente de la edad del niño.

En los niños con asimetría actual y predicha en la adultez $<2 \mathrm{~cm}$, la frecuencia del seguimiento

radiológico puede realizarse cada dos o tres años durante los años prepuberales.

La frecuencia del control radiológico dependerá, además, de la magnitud y de la evc

Durante el seguimiento, es importante evaluar el desarrollo puberal del niño. Se recomienda

el seguimiento junto con el pediatra de cabecera y/o el endocrinólogo infantil.

\section{Predicción de la discrepancia final}

Es necesario utilizar un método de predicción para conocer la discrepancia final al inicio del seguimiento, independientemente de la edad del niño y del tratamiento que se elija.

Si bien no es lo ideal, se recomienda utilizar un método de predicción de la magnitud de la asimetría final, aunque la asimetría no siga un patrón de evolución de Shapiro I.

\section{Planificación del momento de la epifisiodesis}

Es necesario utilizar un método de predicción para conocer el momento óptimo de la cirugía

(epifisiodesis definitiva). El 62,5\% de los expertos prefiere utilizar Multiplier. ${ }^{13}$

Expertos en ortopedia

Acuerdo (\%)

Si bien no es lo ideal, hay que utilizar un método de predicción del momento de la epifisiodesis,

aunque la asimetría no siga un patrón de evolución de Shapiro I.

Es necesario realizar, al menos, dos predicciones del momento óptimo de la epifisiodesis antes de la cirugía para minimizar el error.

Si el niño llega a la consulta ya iniciada la pubertad (consulta tardía), se deberá realizar igual,

al menos, una predicción del momento de la epifisiodesis.

\section{B. Tratamiento}

\section{Realce}

El realce se indicará si, al deambular, se observa que la pelvis bascula,

independientemente de la magnitud de la asimetría.

La altura del realce se evaluará anualmente antes de la pubertad.

La altura del realce se evaluará cada 6 meses durante la pubertad.

La altura del realce se indica con la medición clínica (test de bloques) y radiológica.

En los controles en los cuales no se requiera estimar la asimetría en la adultez ni el momento

óptimo de la epifisiodesis, la magnitud del realce se indicará por la medición clínica (test de bloques).

Cirugía (epifisiodesis de la pierna larga o elongación de la pierna corta)

En la elección del tratamiento quirúrgico, se tendrá en cuenta la edad del niño.

En la elección del tratamiento quirúrgico, se tendrá en cuenta la magnitud de la asimetría actual y predicha. 87,5

En la elección del tratamiento quirúrgico, se tendrá en cuenta la predicción de la estatura final del niño. 100

Para la predicción de la estatura final del niño, se recomienda que trabajen en forma conjunta el ortopedista,

el pediatra de cabecera y/o el endocrinólogo infantil.

Se recomienda utilizar, para la predicción de la estatura final adulta, el método Multiplier. El 62,5\% recomienda realizarlo con la edad ósea.

En la elección del tratamiento quirúrgico, se tendrá en cuenta también la opinión de los padres y del niño, y se analizarán los riesgos y los beneficios de cada una de las técnicas propuestas. 


\begin{tabular}{|c|c|c|}
\hline Afirmación & Acuerdo (\%) & Acuerdo (\%) \\
\hline \multicolumn{3}{|l|}{ Solicitud de la radiografía de los miembros inferiores } \\
\hline $\begin{array}{l}\text { Se debe solicitar la telemetría de los miembros inferiores (imagen en una sola radiografía } \\
\text { de la totalidad de ambas extremidades inferiores, desde la pelvis hasta el tobillo), } \\
\text { en lugar del escanograma (tres exposiciones: cadera, rodillas y tobillos). }\end{array}$ & 100 & 100 \\
\hline $\begin{array}{l}\text { Se debe indicar en la orden de la radiografía al técnico radiólogo la altura y la localización } \\
\text { del realce (pie derecho o izquierdo) de manera de nivelar la pelvis y evitar el error de medición. }\end{array}$ & 100 & 100 \\
\hline $\begin{array}{l}\text { La radiografía se considerará adecuada si incluye la pelvis y los tobillos con las } \\
\text { rótulas centradas y al frente. }\end{array}$ & 100 & 100 \\
\hline $\begin{array}{l}\text { La radiología se realizará en decúbito hasta los } 2 \text { o } 4 \text { años (o antes según la colaboración del niño), } \\
\text { de acuerdo con el tamaño del chasis disponible; a partir de entonces, se realizará de pie } \\
\text { (y con realce si está solicitado en la radiografía). }\end{array}$ & 87,5 & 83,3 \\
\hline \multicolumn{3}{|l|}{ Medición de la radiografía de los miembros inferiores } \\
\hline $\begin{array}{l}\text { La medición radiológica del miembro inferior total se realizará entre el punto más proximal de la } \\
\text { cabeza femoral y el punto medio distal de la tibia "y/o" realizando la sumatoria de los segmentos } \\
\text { (tibia + fémur). Esto dependerá de si el niño presenta compromiso articular, alteración del eje y/o } \\
\text { del número de segmentos afectados. }\end{array}$ & 87,5 & 83,3 \\
\hline $\begin{array}{l}\text { La medición radiológica del fémur se realizará entre el punto más proximal de la cabeza femoral y } \\
\text { el surco intercondíleo. }\end{array}$ & 87,5 & 83,3 \\
\hline $\begin{array}{l}\text { La medición radiológica de la tibia se realizará entre la eminencia intercondílea y el punto medio } \\
\text { de la tibia distal en el tobillo. }\end{array}$ & 100 & 100 \\
\hline
\end{tabular}

modifica el tamaño real del hueso. Los médicos ortopedistas acordaron colocar un patrón de referencia a la altura del niño, pero los expertos en imágenes consideraron que no sería necesario en los sistemas digitales. Del análisis de los argumentos de los expertos surge que esto dependerá del equipo y del software utilizado en cada centro, por lo que se considera prudente que, en cada lugar de trabajo, se generen recomendaciones al respecto para evitar la distorsión del tamaño real de la imagen y el consecuente error de predicción.

La medición radiológica del miembro inferior total se realizará entre el punto más proximal de la cabeza femoral y el punto medio distal de la tibia o sumando cada segmento (tibia + fémur). La elección dependerá de la presencia de compromiso articular o la alteración del eje. Si existiera afectación de los pies, los expertos en ortopedia acordaron incluir el pie en la medición, mientras que los expertos en imágenes consideraron que la inclusión del pie induciría a un error en la medición. De todos modos, se consideró que el ortopedista sería quien especificara, en última instancia, lo que necesitaba para el seguimiento del paciente.

Del análisis de los argumentos de los expertos surge que el ortopedista de cabecera y el médico en diagnóstico por imágenes deberían trabajar en equipo, conociendo las fortalezas y debilidades de cada lugar de trabajo y especificando las necesidades de cada uno para un mejor seguimiento de estos niños.

Si bien el método Delphi tiene sus limitaciones y el nivel de evidencia de consenso de expertos es bajo, este estudio aporta las primeras recomendaciones para el seguimiento clínicoradiológico, la planificación prequirúrgica y el tratamiento de los niños con asimetría de la longitud de los miembros inferiores en nuestro medio y puede ser de mucha ayuda para la atención de los niños con esta afección. Las causas de las asimetrías son múltiples y la evolución es diferente en cada niño, por lo que estas recomendaciones deberán considerarse en cada caso en particular.

\section{CONCLUSIONES}

Estas son las primeras recomendaciones para el seguimiento de los niños con asimetría de la longitud de los miembros inferiores mediante el consenso de expertos.

Un aspecto para destacar surgido en el proceso de consulta fue la importancia del trabajo en equipo entre el ortopedista, el pediatra de cabecera, el especialista en diagnóstico por imágenes y, si fuera necesario, el endocrinólogo infantil, con el objetivo de mejorar la planificación terapéutica. 


\section{REFERENCIAS}

1. Guichet JM, Spivak JM, Trouilloud P, Grammont PM. Lower limb-length discrepancy. An epidemiologic study. Clin Orthop Relat Res. 1991; (272):235-41.

2. Hellsing AL. Leg length inequality. A prospective study of young men during their military service. Ups J Med Sci. 1988; 93(3):245-53.

3. Rush WA, Steiner HA. A study of lower extremity length inequality. Am J Roentgenol Radium Ther. 1946; 56(5):616-23.

4. Herring JA. Limb length discrepancy. En: Herring JA. Tachdjian's Pediatric Orthopaedics: From the Texas Scottish Rite Hospital for Children. 5th ed. Philadelphia: Elsevier Saunders; 2013.Págs.884-948.

5. Miscione H, Goyeneche R. Las implicancias del crecimiento en ortopedia infantil. En: Fano V, del Pino M, Caino S. Ensayos sobre crecimiento y desarrollo. Presentado al Dr. Horacio Lejarraga por sus colegas y discípulos. Buenos Aires: Fundasap-Paidós; 2011.Págs.119-39.

6. Pappas AM, Nehme AM. Leg length discrepancy associated with hypertrophy. Clin Orthop Relat Res. 1979t; (144):198-211.

7. Bianco AJ Jr. Femoral shortening. Clin Orthop Relat Res. 1978; (136):49-53.

8. Broughton NS, Olney BW, Menelaus MB. Tibial shortening for leg length discrepancy. J Bone Joint Surg Br. 1989; 71(2):242-5.

9. Bowen JR. Percutaneous distal femoral or proximal tibial epiphysiodesis. En Flynn JM, Wiesel SW (eds.). Operative Techniques in Pediatric Orthopaedics. Philadelphia:Lippincott Williams \& Wilkins; 2011.Págs.213-8.

10. Pendleton AM, Stevens PM,Hung M. Guided growth for the treatment of moderateleg-length discrepancy. Orthopedics. 2013; 36(5):e575-80.

11. Anderson M, Green WT, Messner MB. Growth and predictions of growth in the lower extremities. J Bone Joint Surg Am. 1963; 45-A:1-14.

12. Moseley CF. A straight-line graph for leg-length discrepancies. J Bone Joint Surg Am. 1977; 59(2):174-9.

13. Paley D, Bhave A, Herzenberg JE, Bowen JR. Multiplier method for predicting limb-length discrepancy.J Bone Joint Surg Am. 2000; 82-A(10):1432-46.

14. LinstoneHA, Turoff M. TheDelphi Method, Techniques and Applications. Illinois: Addison Wesley publishing; 1975.
15. Varela Ruiz M, Díaz Bravo L, García Durán R. Descripción y usos del método Delphi en investigaciones del área de la salud. Investigación Educ Médica. 2012; 1(2):90-5.

16. ShapiroF. Developmental patterns in lower-extremity length discrepancies. J Bone Joint Surg Am. 1982; 64(5):639-51.

17. Diméglio A, Charles YP, Daures JP, de Rosa V, et al. Accuracy of the Sauvegrain method in determining skeletal age during puberty. J Bone Joint Surg Am. 2005; 87(8):1689-96.

18. Westh RN, Menelaus MB. A simple calculation for the timing of epiphysial arrest: a further report. J Bone Joint Surg Br. 1981; 63-B(1):117-9.

19. Friend L, Widmann RF. Advances in management of limb length discrepancy and lower limb deformity. Curr Opin Pediatr. 2008; 20(1):46-51.

20. Sanders JO, Howell J, Qiu X. Comparison of the Paley method using chronological age with use of skeletal maturity for predicting mature limb length in children. J Bone Joint Surg Am. 2011; 93(11):1051-6.

21. Gurney B. Leg length discrepancy. Gait Posture. 2002; 15(2):195-206.

22. Brandy RJ, Dean JB, Skinner TM, Gross MT. Limb length inequality: clinical implications for assessment and intervention. J Orthop Sports Phys Ther. 2003; 33(5):221-34.

23. Gross RH. Leg length discrepancy: how much is too much? Orthopedics. 1978; 1(4):307-10.

24. Bayhan IA, Karatas AF, Rogers KJ, Bowen JR, et al. Comparing percutaneous physeal epiphysiodesis and eight-plate epiphysiodesis for the treatment of limb length discrepancy. J Pediatr Orthop. 2017; 37(5):323-7.

25. Lejarraga $\mathrm{H}$, del Pino M, Fano V, Caino S, et al. Referencias de peso y estatura desde el nacimiento hasta la madurez para niñas y niños argentinos: Incorporación de datos de la OMS de 0 a 2 años, recálculo de percentilos para obtención de valores LMS. Arch Argent Pediatr. 2009; 107(2):126-33.

26. Makarov MR, Dunn SH, Singer DE, Rathjen KE, et al. Complications associated with epiphysiodesis for management of leg length discrepancy. J Pediatr Orthop. 2018; 38(7):370-4.

27. Sabharwal S, Zhao C, McKeon J, Melaghari T, et al. Reliability analysis for radiographic measurement of limb length discrepancy: full-length standing anteroposterior radiograph versus scanogram. J Pediatr Orthop. 2007; 27(1):46-50.

\section{Artículos seleccionados}

Los siguientes resúmenes y comentarios de trabajos seleccionados se encuentran disponibles en la versión electrónica de este número.

European Journal of Paediatrics 2018;177:1279-92

Predictores de la enfermedad de Kawasaki resistente a la inmunoglobulina endovenosa en niños: un metaanálisis de $\mathbf{4 4 4 2}$ casos (Xuan Li , et al. Predictors of intravenous immunoglobulin-resistant Kawasaki disease in children: a meta-analysis of 4442 cases)

Comentario: Dr. Luis Eduardo Urrutia. Hospital Nacional de Pediatría “Juan P. Garrahan”. Ciudad de Buenos Aires

N Engl J Med. 2018 Oct 4;379(14):1303-12

Aceleración del índice de masa corporal en la primera infancia y riesgo de obesidad persistente (Geserick $M$, et al. Acceleration of BMI in early childhood and risk of sustained obesity)

Comentario: Dra. Norma Piazza. Pediatra especialista en Nutrición

Pediatrics. 2018 Jul;142(1). pii: e20180401

Intervenciones para disminuir el dolor en la retinopatía del prematuro: meta-análisis (Disher T, et al. Pain-relieving interventions for retinopathy of prematurity: a meta-analysis)

Comentario: Dr. Ernesto Alda. Docente de la Escuela de Medicina de la UNS - Bahía Blanca 